\title{
DISCURSO DE LA DIRECTORA DE LA ESCUELA DE DERECHO
}

\author{
Luz María Reyes Santelices
}

Aún cuando me parece imposible exponer de viva voz todo aquello que quisiera decir en estos momentos tan significativos para la Escuela de Derecho que me honro en dirigir, intentaré reflexionar ante Uds. sobre el ayer, el hoy y el mañana de esta obra universitaria, iniciada en 1993.

No es mi pretensión dar una cuenta, pero creo que sería impropio no referirme a los tiempos pasados, en que día a día, un grupo de abogados y estudiantes de derecho, con el apoyo decidido y sostenido del Rector Juan Music y de quienes han sido Vicerrectores de Sede, Mario Edding, Exequiel González y Renzo Follegathi, hemos ido dando vida a la Escuela de Derecho, hasta llegar a este momento, en que inauguramos su edificación definitiva.

Nos enorgullece mencionar que los logros alcanzados durante los seis primeros años de la carrera, la han situado en un lugar de privilegio entre sus pares. Es motivo de alegría para nosotros el ver que cada año una cohorte muy grande de los mejores estudiantes de la región prefiere nuestras aulas. Los estudios comparativos que cada año hemos venido realizando del proceso de admisión a las carreras de derecho, nos permiten concluir que a nuestra Escuela ingresan alumnos con los mejores puntajes, en relación a las que han sido creadas en nuestro pais en la última década. Los recibimos con un gran sentido de responsabilidad y nos preocupamos especialmente de la docencia en los primeros años, para que ella sea formativa y para que los alumnos perciban a la Universidad como una institución destinada a servir a su desarrollo personal.

Ellos son el fuego que nos anima en nuestro devenir, a ellos dedicamos nuestros mejores esfuerzos, orientados a descubrir con ellos la verdad, y así conferirles una orientación confiable para su futuro andar por los caminos de la existencia.

En esta búsqueda, una contemplación fecunda y una reflexión que la cuestione, aparecen como fundamentales para desarrollar la capacidad que cada cual trae en su cofre de talentos. Más adelante, en los últimos cursos, la experiencia de vivir, concientemente asumida por ellos, es condición indispensable del empeño que venimos delineando, y es también materia de una ineluctable autoevaluación personal que jamás debiera agotarse en sus vidas.

También esta posición de privilegio puede desprenderse de un estudio realizado por el Colegio de Abogados en 1998. De éste, sólo podemos considerar negativa la cantidad de volúmenes existentes en nuestra biblioteca de derecho, por obvias razones derivadas de su reciente creación, pero debemos reconocer que durante estos años se han realizado en forma sostenida adquisiciones importantes de material bibliográfico y apoyo computacional, esperando contar al año 2.003 con unos 12.000 volúmenes.

Y un Análisis evaluador de la docencia, denominado Estudio del Desarrollo Académico de los alumnos de la Escuela de Derecho de la Sede Coqu'mbo, de la Universi- 
dad Católica del Norte, primer sexenio -1993-1998-, nos permite declarar que la tarea sumida en 1993 se ha desarrollado con criterios claros y definidos. Estos conllevan a enfrentar con decisión y oportunidad las dificultades propias de una carrera en proceso de consolidacion, que son facilmente perceptibles bajo un régimen de evaluación y autoevaluación permanente, cuyo propósito es procurar adecuada retroalimentación a las políticas institucionales y verificar el logro de los objetivos fijados.

Pero desde el principio hemos tenido nítidamente presente que la Universidad exige mucho más que docencia. No obstante la calidad de Escuela que ostenta nuestra unidad académica por decisión de las autoridades universitarias, hemos entendido siempre que es nuestro deber ineludible e impostergable contribuir al desarrollo de todas aquellas actividades que hacen de la Universidad Católica del Norte, una Universidad tradicional y compleja. Para ello, al interior de la Escuela, en una estructura informal, nos hemos agrupado como un cuerpo de personas asociadas con el propósito de enseñar e investigar en un área o áreas afines del conocimiento superior.

Hemos realizado también una fecunda labor de extensión orientada a efectuar un significativo aporte a la cultura en la zona, otorgando, en la consecución de una integración del saber, un lugar preferencial al diálogo entre fe y razón.

La capacitación en temas jurídicos de interés ha sido apreciada por la comunidad regional, habiendo acogido en nuestras aulas a funcionarios del Poder Judicial, de la Policía de Investigaciones de Chile, Gendarmería de Chile, profesionales y empresarios.

En materia de investigación, la convicción que los trabajos propios de nuestra disciplina no son recogidos en revistas indexadas, lo que hace que ese sistema nos resulte imperfecto, y considerando también que por su propia naturaleza tienen un ritmo de publicación muchísimo más lento que otros, nos motivó a editar cada año una Revista de Derecho, que se nutre del producto intelectual de profesores y juristas que visitan nuestra Escuela.

Así, esperamos seguir contribuyendo fielmente a que la Universidad Católica del Norte, cumpla su misión y que en ella se haga vida con pasión, con humildad y con generosidad, la búsqueda de la verdad, compañera y servidora del hombre, siempre sediento de verdad.

Por su parte, nuestros alumnos han sabido responder cabalmente a su condición de estudiantes universitarios, contribuyendo decididamente al prestigio de su Escuela. Tempranamente hemos tenido un primer Licenciado en Ciencias Jurídicas. Y muchos alumnos, a través de nuestra corta historia, se han preocupado de organizar actividades que vayan más allá de lo académico, con el solo y único propósito de contribuir a la expansión del conocimiento y a la discusión de ideas y valores, a la difusión de la cultura y el servicio a los más desposeidos, llevando alegría juvenil y el don de compartir a comunidades aisladas, cooperando también activamente en la lucha contra la drogacción, el alcoholismo y la delincuencia.

Una Escuela de Derecho como la nuestra, que nació hace poco más de un lustro, $y$ que ha tenido un peso considerable en la Universidad y en la sociedad en que se inserta, no la inventamos nosotros. Ella se ha desarrollado, como acontece con las verdaderas instituciones, al compás de las necesidades de la sociedad, y por su propia naturaleza de ente histórico, no se le pueden aplicar esquemas simplistas que a veces son flor 
de un día y que muy bien pudieran estar olvidados mañana. Por el contrario no podemos abdicar a la cautivante y absorbente tarea de guiar todas nuestras acciones hacia metas claramente definidas en el plan de acción, en el marco del plan de desarrollo corporativo de la Universidad, en especial en lo que atañe al difícil camino de la profesionalización y sus correspondientes valores éticos.

Nada de esto lo decimos por un afán de vacía vanagloria, sino movidos por un fuerte sentido de responsabilidad hacia la Universidad que nos cobija, hacia nuestros alumnos y hacia la sociedad toda.

Quisiéramos que al referirnos al sitio que ocupamos hoy, lo hiciéramos sólo para darle gracias a Dios que nos da el querer, el poder y el hacer, y que ha puesto en nuestro camino tan maravillosa oportunidad de desarrollar nuestros talentos.

Conservaremos emotivos e imperecederos recuerdos del Campus Miraflores, donde nació nuestra Escuela de Derecho y en cuyas modestas dependencias se desarrollaron nuestros más caros anhelos, no exentos de sentidas aspiraciones, frustraciones, logros y desencantos. Así, tratando de esquivar las precarias condiciones de infraestructura física en que debieron realizarse las actividades académicas durante los primeros cinco años, nuestra comunidad universitaria de profesores y alumnos se forjó como una casta férrea, unida en torno a grandes ideales y entregando a éstos cada cual lo mejor de sí mismo.

Perdurará siempre en nuestra memoria ese entorno natural que al abandonar el campus en cada atardecer, nos hacía reflexionar que nuestra Escuela de Derecho crecía, bajo el paso inexorable del tiempo. Las rosas trepadoras del muro norte, la fragancia d e los clarines, las azucenas de noviembre y nuestros alumnos estudiando alrededor de la gruta de la virgen, bajo la generosa sombra de las añosas vilcas, nos indicaban el término de cada año académico y la imperiosa necesidad de programar el siguiente con mayor entrega, con más fuerza y creatividad, con mucho amor. Asi fueron cobrando vida los avances que hemos mencionado anteriormente.

Al mismo tiempo, una inquietante preocupación fue motivo de desazón para profesores y alumnos. Si constituía un interés fundamental situar a nuestra Escuela de Derecho en un lugar de privilegio entre sus pares, y frente a la sociedad, debía ésta contar con espacios físicos adecuados para el desarrollo de sus actividades en un nivel de excelencia. La definición del lugar en que se construiría el edificio de la Escuela de Derecho fue el resultado de profundas reflexiones y de divergentes opiniones y no resultó fácil acoger propuestas que para los abogados en general no eran convincentes. $Y$ es así como se realizaron ingentes esfuerzos para lograr el establecimiento de la Escuela cerca de los centros de interés jurídico, los que en algún momento se vieron coronados con logros importantes que han beneficiado a la Universidad Católica del Norte.

Nos embarga una gran emoción y profundo reconocimiento al recordar que en este intento se contó con el decidido y leal apoyo de autoridades regionales y de profesores y alumnos, muchos de ellos hoy exalumnos de la Escuela ,quienes se mostraron como una comunidad firmemente cohesionada y armónica, en torno a lo que creímos lo mejor para el futuro de nuestro proyecto académico.

Pero la Universidad es una institución y como tal debía resguardar sus legítimos intereses, a través de sus órganos unipersonales y colegiados que decididamente propiciaron la integración de la Escuela de Derecho al Campus Guayacán. A través de mu- 
chas coyunturas y tensiones se produce a fines de 1997 la esperada decisión y descle ese momento hemos sabido respetarla y comprender que lo especifico de nuestra misión exigía un espíritu de cuerpo y un sacrificio generoso de muchas legítimas aspiraciones individuales.

\section{Estimados amigos, amigas,}

Los tiempos de Miraflores han quedado atrás.

Hoy, al iniciar nuestras actividades académicas en el Edificio construido para la Escuela de Derecho, en Guayacán, auguramos a este campus universitario un futuro pleno de prestigio académico, que con el tiempo pueda imprimir a esta zona una gran presencia universitaria , al estilo de Aix en Provence, en Francia, Heidelberg en Alemania, Uppsala en Suecia y Lovaina en Bélgica.

$Y$ también declaramos públicamente ante la comunidad universitaria toda, nuestra más firme intención de promover una real integración y contribución de directivos, profesores, alumnos y administrativos, al inapreciable mundo académico que se nos ofrece en el Campus Guayacán, en aras del engrandecimiento siempre creciente de la Universidad Católica del Norte.

Reitero hoy las palabras que pronuncié en diciembre de 1997, en la ceremonia de celebración del quinto aniversario de la Escuela de Derecho y despedida de sus primeros egresados. Decía en esa ocasión :

"Anhelamos contribuir a que esta Casa de Estudios sea cada vez más y mejor una Universidad Católica y Humanista. Sólo en ella nuestra Escuela de Derecho podrá dar sus mejores frutos, procurando siempre el mérito en todas sus actividades y optando decididamente por estudiar, investigar, enseñar y difundir a partir de la tradición ética y jurídica que remonta de judíos, griegos, romanos y cristianos. Ello exigirá la colaboración de todos sus integrantes: autoridades, profesores, alumnos y funcionarios. La práctica sencilla y anónima de la virtud, la solidaridad efectiva y silenciosa, el compromiso con una educación que informe, forme e incluso reforme, la apertura universal y la tolerancia, un espíritu familiar y una comunidad de destinos : tales son algunas de las condiciones para que nuestra Escuela, como parte de la Universidad Católica del Norte, logre obtener sus más caros anhelos."

$Y$ es necesario considerar que la Universidad es humanista no por priorizar las humanidades, sino por su vinculación al hombre: a todo el hombre, a todos los hombres, a cada hombre.

Hoy es un día de alegría y de gratitud. Podemos mirar el futuro con la confianza que otorga el haber logrado una excelente solución al único problema de la Escuela de Derecho, que escapaba de nuestro ámbito de decisiones y el saber que la labor desarrollada durante estos años ha sido favorablemente apreciada por las autoridades universitarias.

De alegría, porque las instalaciones que se nos entregan permitirán acoger en la mejor forma a profesores y alumnos y programar con ellos y para ellos, variadas e interesantes actividades académicas. Hemos comprometido ya a nuestra Escuela de Derecho como sede de las segundas Jornadas de Derecho Minero, a realizarse en noviembre próximo, de las Jornadas sobre Análisis y discusión de la Reforma Procesal Penal, de un 


\section{Discursos}

Ciclo de Conferencias sobre la Libertad, como derecho esencial de la persona humana, cursos de extensión y de capacitación y otras actividades de real envergadura.

Nos proyectamos hacia el nuevo siglo con gran optimismo, y con miras a conferirle a nuestra Escuela de Derecho mayores expectativas académicas, que la sitúen en un plano de igualdad con Facultades de Derecho de prestigio y tradición.

Es también un momento de gratitud. En nombre propio y de la comunidad de profesores y alumnos de la Escuela de Derecho, deseo expresar nuestro sincero y especial agradecimiento a los integrantes del Consejo Superior de la Universidad Católica del Norte.

Agradecemos al Rector de la Universidad y a quienes eran a la sazón Vicerrector de sede y Secretario de Sede, los académicos Mario Edding y Alfonso Silva, la acertada decisión de crear una Escuela de Derecho en la sede Coquimbo.

Nuestra gratitud también hacia el rector don Juan Music Tomicic, por el inapreciable apoyo que ha brindado a nuestra Escuela desde su creación y la confianza depositada en quienes hemos sido actores de su devenir. El rector Music ha sabido comprender las implicancias de la creación al interior de la Universidad, de una carrera de Derecho por tradición distinta a otras carreras universitarias y su personal preocupación culmina hoy con la consolidación física tan necesaria para el mayor éxito de cualquier actividad académica. Si bien es cierto la infraestructura física no es lo más importante, así lo comprobamos en el Campus Miraflores, sino que lo son las personas que le dan vida, no es menos cierto que los espacios físicos adecuados invitan al trabajo bien hecho, al intercambio académico, a la reflexión, a la paz espiritual.

Reconocemos en la gestión del Rector, el dinamismo y clara visión que ha permitido un importante y sostenido crecimiento y prestigio de la Universidad Católica del Norte, como asimismo el saber conjugar armoniosamente el ejercicio eficaz de la autoridad con la creatividad de la comunidad universitaria.

Esta tarde, el mejor reconocimiento que podemos entregarle, es ofrecer a la Universidad Católica del Norte nuestra lealtad y esfuerzo para seguir avanzando en la senda de la excelencia y el progreso.

A contar de hoy, y gradualmente el ambiente casi familiar en que todos nos conocíamos, irá dando paso a un entorno cada vez más universitario. Aflorarán distintos intereses y formas de expresión que sin embargo no debilitarán el fuerte espíritu de cuerpo nacido espontáneamente en los tiempos de Miraflores y el deseo ferviente de efectiva integración y amistad hacia quienes nos han precedido en el Campus Guayacán y de quienes esperamos aprender a hacer Universidad.

Finalmente deseo manifestar que permaneceremos fieles a los principios orientadores originales de nuestra Escuela de Derecho y sobre ellos continuaremos edificando el futuro, parafraseando día tras día , a aquel sembrador del poema de todos conocido, del poeta Blanco Belmonte : hay que vivir sembrando, siempre sembrando.

Como en los tiempos de Miraflores. 